\title{
ESTRUTURAS E NOMENCLATURAS DOS HIDROCARBONETOS: É POSSÍVEL APRENDER JOGANDO?
}

\author{
C. A. B. SILVA JÚNIOR* e A. M. C. BIZERRA \\ Instituto Federal de Educação, Ciência e Tecnologia do Rio Grande do Norte \\ carlosjuniorquimico@hotmail.com*
}

Artigo submetido em outubro/2015 e aceito em novembro/2015

DOI: $10.15628 /$ holos.2015.3616

\section{RESUMO}

Muitos estudantes do Ensino Médio apresentam dificuldades no entendimento de alguns assuntos relacionados à Química, como por exemplo, o estudo de nomenclatura dos compostos orgânicos. Estas dificuldades podem estar atreladas a falta de interesse e de motivação dos alunos, que unidas aos métodos de ensino, pouco atrativos, não permitem que estes consigam concretizar o conhecimento. Este trabalho enfoca a aplicação de um jogo como proposta pedagógica facilitadora para o ensino de nomenclatura dos hidrocarbonetos. O objetivo deste jogo é proporcionar, ao aluno, uma aula motivadora, que desperte o seu interesse neste conteúdo e que, por consequência, permita o seu aprendizado. Serão discutidas as etapas de aplicação e avaliação da proposta do "Jogo do Sim ou Não" como um instrumento pedagógico facilitador que pode ser útil nas aulas de Química Orgânica.

PALAVRAS-CHAVE: Jogo; Motivação; Aprendizagem

\section{STRUCTURES AND NOMENCLATURE OF HYDROCARBONS: YOU CAN LEARN PLAYING?}

\begin{abstract}
Many high school students have difficulties in understanding some issues related to chemicals, such as the study of nomenclature of organic compounds. These difficulties can be linked to lack of interest and motivation of students who joined the teaching methods, unattractive, do not allow these able to realize the knowledge. This work focuses on the application of a game as a facilitator for the pedagogical proposal of
\end{abstract}

hydrocarbons naming education. The objective of this game is to provide to the student, a motivating class, to arouse their interest in content and therefore allow your learning. The application steps and evaluation of the proposal will be discussed the "Game Yes or No" as a facilitator teaching tool that can be useful in organic chemistry classes.

KEYWORDS: Game; Motivation; Learning. 


\section{INTRODUÇÃO}

A Química, enquanto disciplina curricular, apresenta fundamental importância, visto que ela é essencial para o desenvolvimento da sociedade. Através dela podem-se buscar inovações em várias áreas do conhecimento científico, tais como: a medicina, com os fármacos, a geologia, com o estudo das composições dos solos, as engenharias tecnológicas e alimentícias e etc. É possível, ainda, obter explicações sobre vários questionamentos e fenômenos que ocorrem em nosso cotidiano. Por esse motivo se torna imprescindível ao currículo do Ensino Básico e deve ser discutida em sala de aula levando-se em consideração não só as dimensões científicas, como também as sociais e culturais.

No entanto, essa relevância não é reconhecida e nem aproveitada pela maioria dos alunos. O que se observa na rotina de grande parte das aulas de Química é a falta de interesse por parte de muitos alunos. Pode-se atribuir a esse fato, as dificuldades encontradas pelos estudantes na assimilação dos conteúdos dessa disciplina. Cardoso (2000) afirma que estudantes do ensino médio geralmente demonstram dificuldades para assimilar alguns conceitos científicos nas disciplinas que compõem as ciências exatas como a Química. Gibin (2009) afirma que os alunos do Ensino Médio têm dificuldades para aprender Química e geralmente não conseguem estabelecer relações apropriadas entre os níveis macroscópico, simbólico e o submicroscópico.

Sobre isso, Nunes e Adorni (2010) afirmam que no ensino da Química, observam-se alunos que muitas vezes não conseguem aprender e não são capazes de associar o conteúdo estudado com seu cotidiano, por isso perdem o interesse. Desta forma percebe-se que muitas vezes o ensino desta disciplina está sendo feito de forma descontextualizada e não interdisciplinar.

Com relação a esse assunto, Trevisan e Martins (2006) afirmam que é necessário falar em educação química, levando-se em consideração a sua contextualização com os fenômenos e acontecimentos do cotidiano do aluno, para que estes percebam sua importância socioeconômica, numa sociedade avançada, tanto no sentido tecnológico quanto no sentido social.

Diante das dificuldades encontradas no ensino de Química percebe-se que é necessário se trabalhar com novas possibilidades, estratégias ou propostas pedagógicas facilitadoras que possam proporcionar o estreitamento da relação ensino-aprendizagem nesta disciplina. Segundo Moreira (2012), a elaboração de um material didático que seja potencialmente significativo, pode proporcionar, no aluno, uma motivação para estudar e aprender Química, porém esse material deve ser elaborado de uma forma que permita a integração entre o conhecimento prévio do aluno e a nova informação apresentada pelo professor.

Uma alternativa pedagógica para sanar essas dificuldades no ensino desta disciplina é a aplicação de jogos químicos como instrumentos lúdicos. Segundo Benedetti et al $(2009$, p. 89) "o uso do lúdico para ensinar conceitos em sala de aula pode ser uma ferramenta que desperte o interesse da maioria dos alunos, motivando-os a buscar soluções e alternativas que resolvam e expliquem as atividades lúdicas propostas". Essa falta de interesse por parte do estudante deve ser vista com outros olhos pelo professor que preza pelo aprendizado de seus alunos. Segundo Cavalcanti, Deus e Soares (2007, p. 1), “o jogo é um instrumento que desperta o interesse, devido ao desafio que ele impõe ao aluno. O aluno desafiado busca, com satisfação, a superação de seu obstáculo, pois o interesse precede a assimilação". 
Robaina (2008, p. 12) defende a utilização dos jogos pedagógicos, afirmando ser uma alternativa viável e promissora, já que podem ser confeccionados com materiais que fazem parte do ambiente de sala de aula ou que são descartados nas residências. É justamente essa a ideia da aplicação do lúdico em sala de aula, a de levar em consideração tanto a facilidade de assimilação do conteúdo, quanto à confecção dos jogos, pois isso contribui para que os alunos se utilizem da sua criatividade e se tornem construtores do próprio conhecimento, desenvolvendo, inclusive, seus próprios jogos. Para ratificar essa ideia, $\operatorname{Nardin}(2008$, p.4) afirma que "a construção de um espaço de jogo, de interação e de criatividade proporcionaria o aprender com seu objetivo máximo, com sentido e significado, no qual o gostar e o querer estariam presentes".

A respeito dos jogos químicos, Soares (2004, p. 180) diz que é possível despertar o interesse do aprendiz para o ensino de química, fazendo-se jogos que busquem representar os eventos microscópicos e abstratos de forma macroscópica e palpável. Os jogos Químicos em sala de aula, segundo Cunha (2012, p. 96) podem e devem ser utilizados como recursos didáticos na aprendizagem de conceitos. Estes podem auxiliar na aprendizagem dos estudantes, sendo utilizados como recurso mediador/facilitador para a obtenção da informação por estes.

Essa dificuldade que os alunos encontram para aprender alguns assuntos de Química é preocupante, por isso é necessário que os professores se utilizem de algum recuso inovador que possa suprir essa dificuldade. Um dos assuntos que os estudantes encontram mais dificuldades é o que está relacionado a nomenclatura dos compostos orgânicos, pois este assunto envolve um número consideravelmente elevado de informações.

Este trabalho objetiva mostrar a aplicação, bem como os resultados desta aplicação, de um jogo que foi executado em quatro turmas de duas escolas diferentes. Este foi utilizado como ferramenta pedagógica facilitadora no ensino de nomenclatura dos hidrocarbonetos. É também objetivo deste trabalho, analisar a influência do jogo, não só nas notas dos alunos, como também no interesse/motivação destes mediante a aula com esta ferramenta didática.

\section{O JOGO DO SIM OU NÃO}

Este jogo pode ser utilizado em sala de aula como uma ferramenta pedagógica alternativa que pode contribuir para o entendimento dos assuntos relacionados à nomenclatura dos compostos orgânicos, principalmente os hidrocarbonetos e os compostos oxigenados e nitrogenados. A finalidade do "Jogo do Sim ou Não" neste trabalho é fazer com que os alunos consigam identificar, com precisão, todas as classes dos hidrocarbonetos tais como: alcanos, alcenos, alcinos e outras. Este também pode ser utilizado para auxiliar na compreensão dos compostos oxigenados (álcoois, aldeídos, cetonas e outros) e nitrogenados como as aminas, aminas, nitrilas e etc.

O Jogo do "Sim ou Não" proporciona uma aula dinâmica e motivadora, pois permite que todos participem de uma competição instigante. Essa "atmosfera" de competição desperta nos alunos uma vontade de aprender mais sobre os assuntos relacionados às nomenclaturas dos compostos orgânicos, visto que o desejo de grande parte deles é de ser vencedor da competição. Além de tudo é de fácil aplicabilidade, pois, para a sua realização, basta dispor apenas de caneta, papel e livro de Química. 
O jogo é uma competição entre os grupos da sala de aula que são previamente divididos. 0 objetivo do jogo está em descobrir o nome de uma estrutura orgânica que o professor escolhe e guarda para que ninguém possa ver. Essa estrutura pode ser um hidrocarboneto, um composto oxigenado ou um nitrogenado, isso vai depender do assunto que o professor ministrou.

O professor além de intermediador também é participante do jogo. Os grupos deverão elaborar perguntas que serão feitas a ele, de modo que este só poderá responder "sim ou não" (por isso que o jogo recebe este nome). Então as perguntas precisam ser bem elaboradas, pois do contrário, o professor não poderá respondê-las. Se, por exemplo, o grupo fizer a seguinte pergunta: "Qual o número de carbonos que este composto (escondido) apresenta na cadeia principal?", com certeza este grupo não obterá resposta, pois não tem como o professor responder sim ou não. Por outro lado, se esta equipe perguntar o seguinte: "Neste composto, o número de carbonos na cadeia principal é igual a seis?", desta forma a resposta poderá ser sim ou não.

Qualquer material didático, como livro, apostila, caderno ou até mesmo a internet, pode ser utilizado pela equipe para elaborar as perguntas e tentar descobrir as respostas. Estas perguntas objetivam obter informações a respeito da estrutura escolhida pelo professor. Em cada rodada de perguntas as equipes descartam as possibilidades e se aproximam mais da nomenclatura correta.

\subsection{Regras do jogo}

1. No início do jogo, o professor escolhe os grupos que podem ser divididos de qualquer forma. Estes devem conter o mesmo número de componentes, ou seja, divide-se o número total de alunos pela quantidade de equipes participantes. Também será sorteada uma numeração para cada equipe;

2. Cada equipe poderá fazer apenas uma pergunta por rodada. No entanto, se esta equipe, depois da resposta do professor, montar uma possível resposta para a nomenclatura da substância que se deseja descobrir, poderá arriscar a resposta, sem necessidade de esperar a rodada se completar até novamente chegar a sua vez;

3. Não haverá perda de pontos se a equipe errar qualquer resposta, apenas passará a vez para o próximo grupo e esperará sua chance novamente, isso se antes nenhum outro descobrir a nomenclatura correta;

4. Se alguma equipe já conseguir a resposta, não poderá responder antes que chegue sua oportunidade de responder;

5. A equipe que acertar a resposta ganhará um ponto e quando isso ocorre, o professor elabora outra estrutura e o jogo recomeça com o grupo com numeração seguinte ao que iniciou anteriormente, por exemplo, se o grupo 2 começou antes, agora o 3 começará e assim sucessivamente;

6. Vence o jogo a equipe que acumular o maior número de pontos, ou seja, a que acertar o maior número de nomenclaturas.

\section{METOdOLOGIA}

Para a realização desta pesquisa foram escolhidas quatro turmas, três da Escola Estadual Gabriel Epifânio dos Reis, da cidade de Icapuí, no Ceará e uma do Instituto Federal do Rio Grande 
do Norte (IFRN) campus Ipanguaçu. As turmas escolhidas da escola Gabriel foram as de terceiros anos $\left(3^{\circ} \mathrm{A}, 3^{\circ} \mathrm{B}\right.$ e $3 \circ \mathrm{C}$ ) do Ensino Médio, já a do IFRN, correspondia a de Técnico de Nível Médio em Meio Ambiente, na forma Subsequente (será chamada de SUBMAMB). Todas as quatro turmas apresentavam números de alunos entre 33 e 36 . Nelas, o mesmo procedimento metodológico, de igual forma, foi empregado.

Inicialmente, houve a ministração dos conteúdos teóricos relacionados ao estudo das estruturas e nomenclaturas de todas as subclasses de hidrocarbonetos. Para esta etapa foram utilizadas seis aulas, divididas em dias diferentes, mas, consecutivos. Depois disso, em duas aulas de outro dia, ocorreu a aplicação da avaliação "pré-jogo", que recebe este nome por ter sido aplicada antes da execução do "Jogo do Sim ou Não". Nela, continham duas questões, uma com vários itens com estruturas de hidrocarbonetos que deveriam ser nomeadas e outra com vários nomes de compostos que precisavam ser postos em suas formas estruturais.

Depois, ocorreu a aplicação do "Jogo do Sim ou Não". Para isso, foram utilizadas quatro aulas que ficaram divididas em dois dias. Na a realização deste jogo, a sala de aula, de cada turma estudada, foi dividida em seis grupos de cinco ou seis alunos. O jogo começou com o professor desenhando uma estrutura de um hidrocarboneto, com sua respectiva nomenclatura, em um pedaço de papel que foi depois guardado em uma caixa de papelão, isto para que nenhum aluno tivesse contato com a resposta. As equipes precisavam se organizar de forma que não pudessem entrar em contato umas com as outras. Os grupos foram numerados de um a seis.

Nas duas escolas, o jogo foi iniciado nas aulas de um dia e terminado nas aulas seguintes, em outro dia. Foi levada em consideração a pontuação das equipes nos dois dias de aplicação do jogo. Venceu a equipe que conseguiu acumular o maior número de pontos, ou seja, o grupo vencedor foi aquele que conseguiu elaborar corretamente o maior número de estruturas e as respectivas nomenclaturas dos hidrocarbonetos que o professor escolheu nos dois dias.

No encontro posterior, foi aplicada, em duas aulas, a avaliação intitulada por "pós-jogo". Esta continha o mesmo formato estrutural da "pré-jogo", também possuía o mesmo nível de dificuldade da primeira. Os resultados das duas avaliações foram utilizados para que se pudesse analisar a contribuição do jogo proposto na aprendizagem dos alunos no conteúdo trabalhado.

\section{RESULTADOS E DISCUSSÃO}

No período de ministração das aulas teóricas observou-se que os alunos, em ambas as escolas, apresentavam muitas dificuldades de compreensão do assunto, principalmente no que se diz respeito ao entendimento das nomenclaturas das subclasses dos hidrocarbonetos, bem como suas respectivas estruturas. Foram perceptíveis as deficiências apresentadas na resolução dos exercícios tanto de sala de aula quanto, principalmente, os elaborados para casa. Esse fato pode ser comprovado através da análise dos gráficos apresentados na Figura 1. Esta mostra o desempenho dos alunos das quatro turmas na avaliação realizada após o período de ministração dessas aulas. 


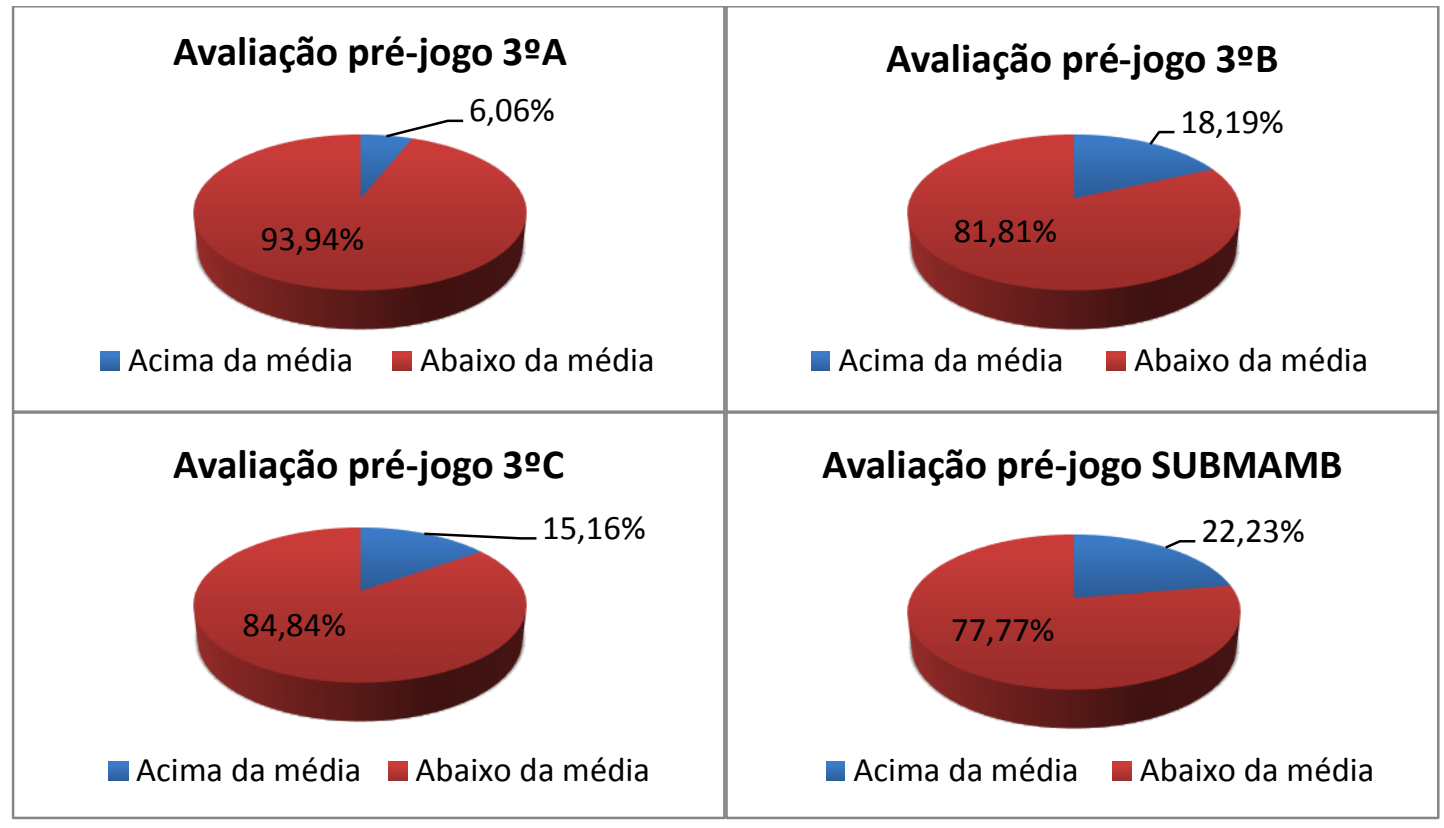

Figura 1: Desempenho dos alunos dos na avaliação "pré-jogo".

Analisando-se os resultados apresentados, observa-se, em todas as turmas, um percentual muito grande de notas abaixo da média seis. Em nenhuma delas houve aprovação acima de $25 \%$, comprovando o que já se havia observado no decorrer das aulas teóricas, isto é, a grande maioria não conseguia compreender efetivamente o conteúdo trabalhado.

Observa-se também que até a turma de SUBMAMB, que é de uma instituição federal, que supostamente é detentora de mais recursos e melhores estruturas, se comparada com as três turmas da escola estadual, também obteve desempenho insatisfatório. Isso comprova que as dificuldades apresentadas pelos alunos vão além da disposição estrutural da escola. Neste caso os métodos de ensino apresentam um peso mais significativo.

Ao ser iniciado o jogo, percebeu-se que nem todos os alunos dos grupos se envolviam, porém, com o passar do tempo e com o aumento da disputa entre as equipes, observou-se que quase todos os alunos encontravam-se participantes. $O$ envolvimento era tão grande por parte dos alunos, que estes não queriam parar de jogar. Em SUBMAMB e na turma do 3 ํㅡ, os estudantes pediram ao professor para que não houvesse intervalo e assim o jogo pudesse continuar.

Os estudantes estavam muito motivados em descobrir as nomenclaturas das substâncias que o professor escondia na caixa. No decorrer do jogo, já se percebia a evolução de alguns alunos que conseguiam diferenciar facilmente as famílias dos hidrocarbonetos. Depois da realização do "Jogo do Sim ou Não", muitos apresentavam uma grande evolução no entendimento da aplicação dos prefixos e radicais utilizados na montagem das nomenclaturas dos hidrocarbonetos.

Na aplicação da avaliação "pós-jogo", percebeu-se que os alunos demonstravam uma facilidade maior no entendimento das questões, sendo que alguns argumentavam que esta avaliação estava mais fácil que a avaliação "pré-jogo". Os gráficos dos resultados dessa avaliação se encontram na Figura 2. 


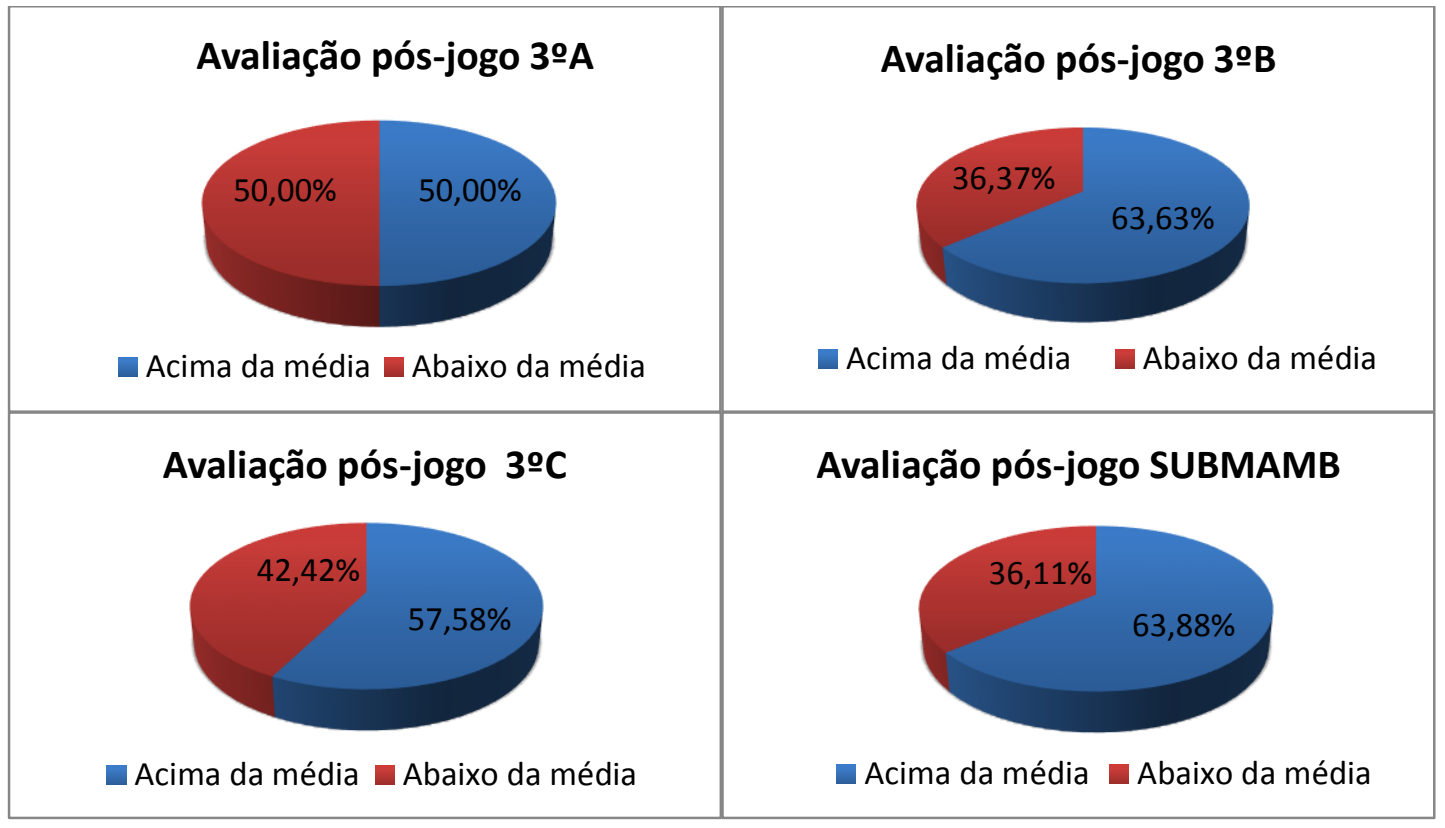

Figura 2: Desempenho dos alunos dos na avaliação “pós-jogo”.

Analisando-se esses resultados, pode-se perceber que os alunos, nas quatro turmas, apresentaram evolução significativa em suas notas depois do período de aplicação do "Jogo do Sim ou Não". Aqui se percebe que houve um percentual maior de alunos que conseguiram atingir ou ultrapassar a nota seis, se for comparado com os resultados obtidos na avaliação anterior.

No entanto, é possível perceber que apesar da evolução depois do jogo, muitos alunos ainda apresentaram desempenho insatisfatório, isto é, vários ficaram, ainda, abaixo do esperado, sendo alguns destes com desempenho pior que da avaliação anterior. Para compreender melhor a análise desses resultados, basta observar os gráficos (1, 2, 3 e 4) a seguir.

Notas dos alunos do 3ำA antes e depois do jogo

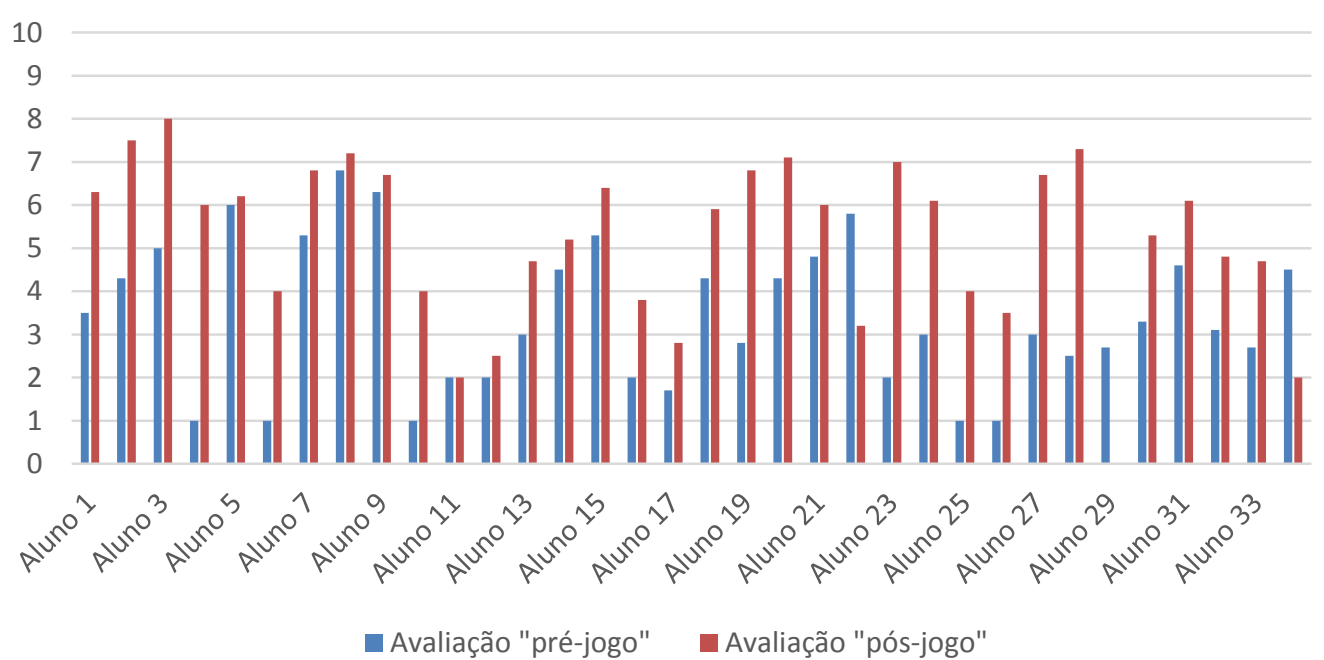

Gráfico 1: notas dos alunos do 3A nas duas avaliações. 
Notas dos alunos do 3ํㅡ antes e depois do jogo

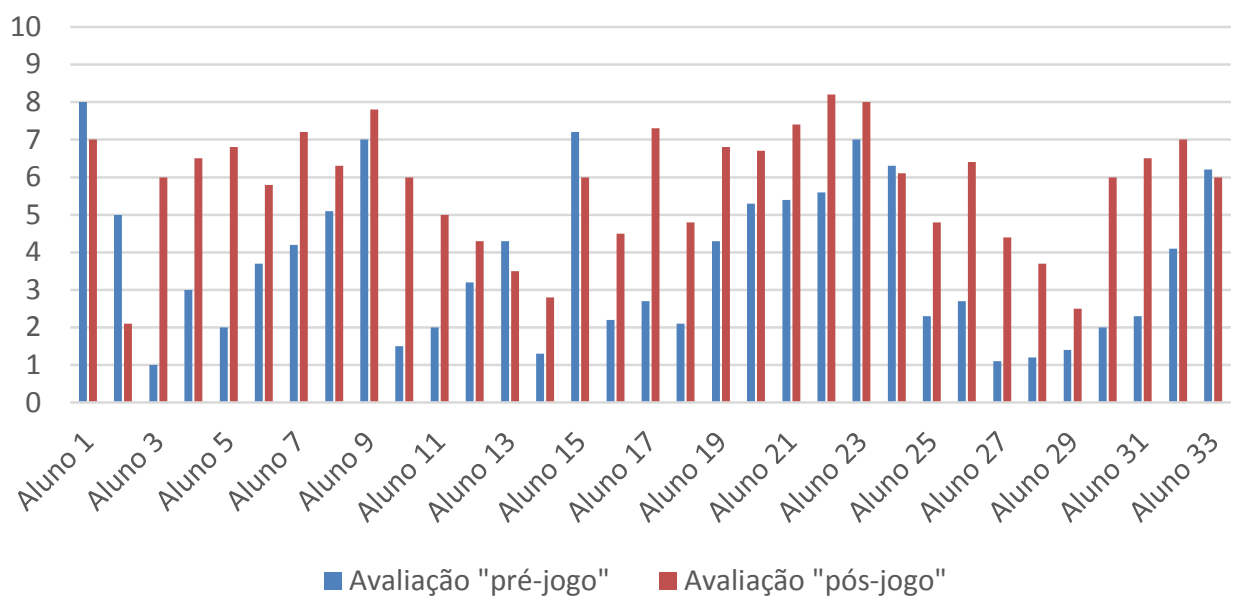

Gráfico 2: notas dos alunos do 3B nas duas avaliações.

Notas dos alunos do 3 으 antes e depois do jogo

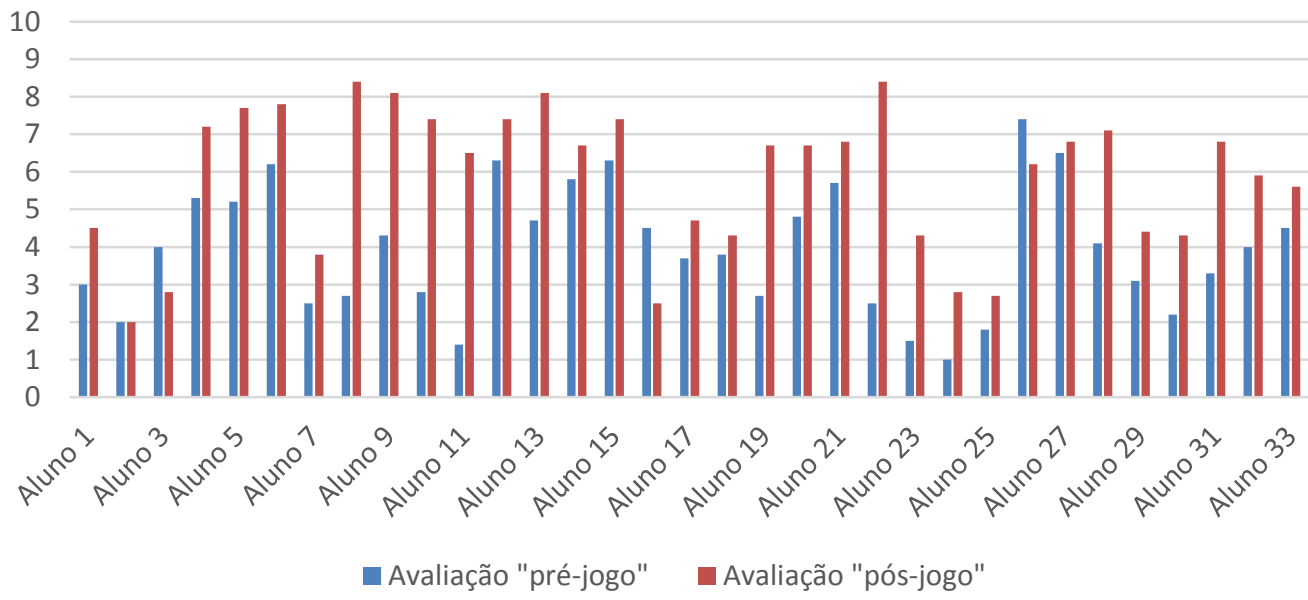

Gráfico 3: notas dos alunos do 3ำ nas duas avaliações.

Notas dos alunos de SUBMAMB antes e depois do jogo

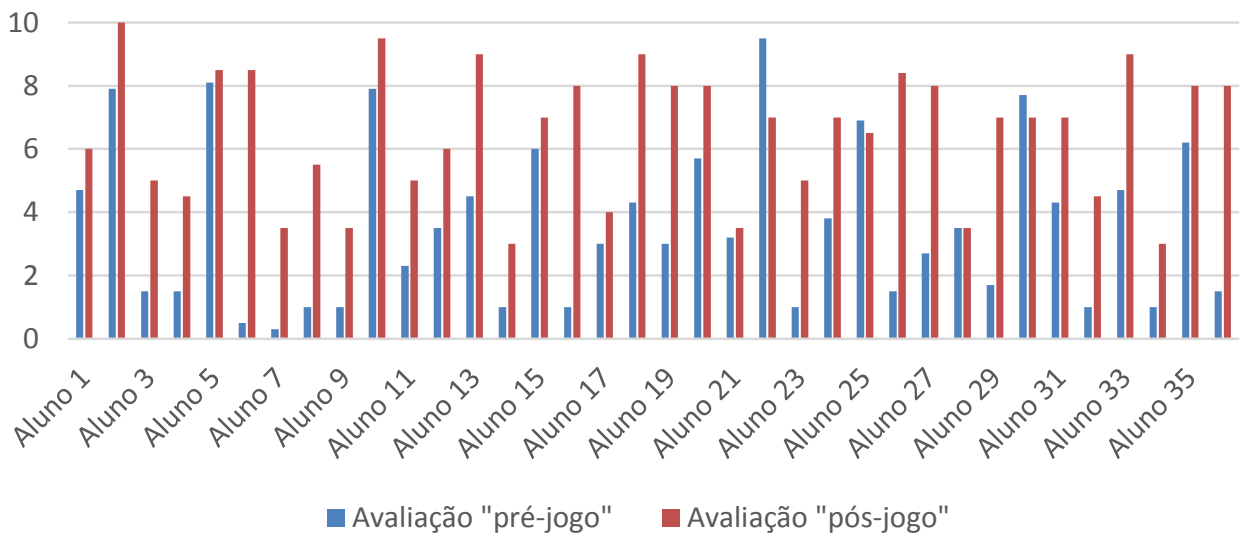

Gráfico 4: notas dos alunos de SUBMAMB nas duas avaliações. 
Através da análise desses gráficos, percebe-se a influência positiva do "Jogo do Sim ou Não" nas notas dos alunos. Por mais que alguns estudantes não tenham melhorado seu desempenho, ficando, alguns, com notas mais baixas depois da aplicação do jogo, nota-se que a aplicação deste foi determinante para que houvesse essa importante elevação.

Se for feita uma análise mais otimista, é possível notar, também, que mesmo alguns alunos que ficaram abaixo de seis apresentaram melhora depois da aplicação do jogo. Na figura 3 estão os percentuais de alunos, independente do valor das notas, que conseguiram melhorá-las.

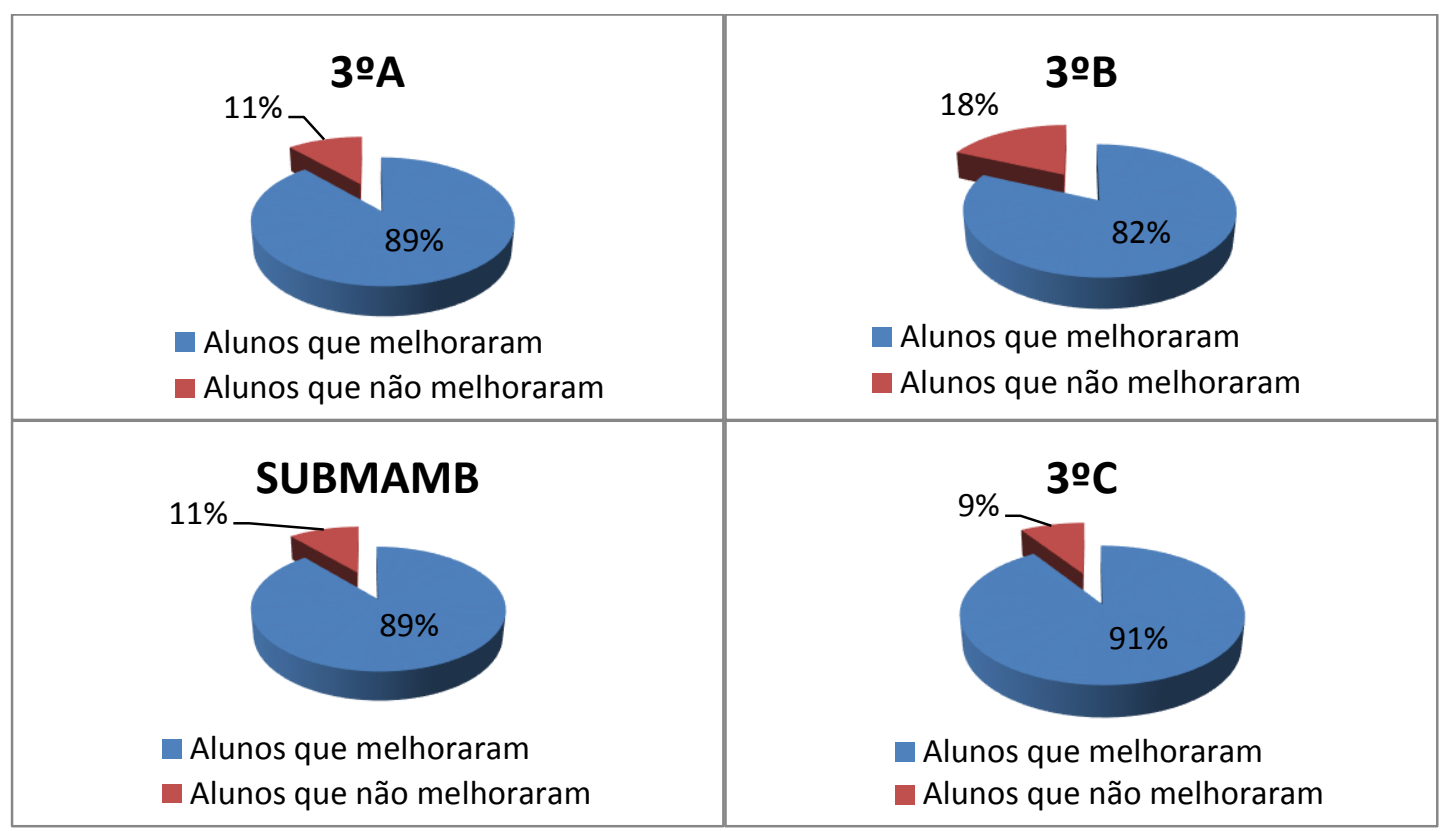

Figura 3: Percentual de alunos que aumentaram na avaliação “pós-jogo” em relação a avaliação “pré-jogo”.

\section{CONSIDERAÇÕES FINAIS}

Os resultados obtidos mediante a aplicação do "Jogo do Sim ou Não", nas quatro turmas pesquisadas, levam a crer que o emprego de jogos como recurso pedagógico nas aulas de Química, se constitui como uma alternativa para que estas se tornem mais prazerosas e efetivas, visto que, neste caso, foi observada uma grande motivação e envolvimento dos alunos nas aulas que envolveram a aplicação do jogo.

No que concerne ao entendimento dos conteúdos, pode-se afirmar, com base nos resultados obtidos, que o jogo foi fundamental para que boa parte dos alunos conseguisse entender, diferenciar e tratar da nomenclatura dos hidrocarbonetos. Antes do jogo os alunos não conseguiam saber diferenciar nem mesmo um hidrocarboneto do outro e nem fazer a nomenclatura de uma determinada estrutura. Por outro lado, depois que o jogo foi trabalhado em sala, os alunos já conseguiam facilmente identificar os hidrocarbonetos e suas respectivas nomenclaturas.

É bem verdade que o jogo não pôde sanar todas as dificuldades, pois alguns alunos não conseguiram avançar na compreensão do assunto trabalhado. Por isso não se pode utilizar esse ou qualquer outro jogo didático com o intuito de resolver todos os problemas de aprendizado apresentadas pelos alunos. 
Vale ressaltar que o jogo por si só não sanará as dificuldades dos alunos em qualquer conteúdo. É necessário que haja um planejamento efetivo que leve em consideração os verdadeiros objetivos que devem ser alcançados, sem esquecer-se das possíveis dificuldades que poderão ser encontradas, do contrário a aula perderá seu sentido didático-pedagógico.

Contudo, ficou comprovado que o "Jogo do Sim ou Não", pode ser visto como uma ferramenta pedagógica auxiliadora muito útil e capaz de proporcionar um estreitamento entre a relação ensino-aprendizagem. Fazendo com que muitos alunos conseguissem aprender boa parte do conteúdo ministrado. Pode-se destacar, ainda, sua relevância para aplicações futuras, também por outros professores, visto que foi alcançado êxito em sua execução.

\section{REFERÊNCIAS}

1. BENEDETTI, E.F; FIORUCCI, A.R; PIRES, L.S.B; ALVES, J.C. Palavras cruzadas como recurso didático no ensino de teoria atômica. Química nova na escola, vol.31, n², p.88-95, 2009.

2. CAVALCANTI, E.L.D.; DEUS, T.C. e SOARES, M.H.F.B. Perfil químico: um jogo didático para promover a interação e o conhecimento. In: Anais. 30a Reunião Anual da Sociedade Brasileira de Química, 2007. Disponível em: < http://sec.sbq.org. br/cdrom/30ra/resumos/T05651.pdf>.Acesso em: 18 Dez. 2013.

3. CARDOSO, S. P.; COLINVAUX, D. Explorando a Motivação para Estudar Química. Revista Química Nova, São Paulo, SP, v. 2, n. 23, p. 401-404, set.1998/dez. 1999, 2000.

4. CUNHA, M. B. Jogos no Ensino de Química: Considerações Teóricas para sua Utilização em Sala de Aula. Química Nova na Escola, vol.34, n² 2, p.92-98, maio 2012.

5. GIBIN, G. B. Investigação sobre a Construção de Modelos Mentais para o Conceito de Soluções por meio de Animações. 2009. 124p. Dissertação de mestrado (Programa de PósGraduação em Química)-UFScar, São Carlos, SP.

6. MOREIRA, M. A. Aprendizagem significativa: da visão clássica à visão crítica. Disponível em: < http://www.if.ufrgs.br/ moreira/visaoclasicavisaocritica.pdf >> Acessado em 14/12/12.

7. NARDIN, I. C. B. "Brincando aprende-se química". Disponível em: www.diaadiaeducacao. pr.gov.br/portals/pde/arquivos/688-4.pdf. Acesso em 16 de junho de 2011.

8. NUNES, A. S. ; ADORNI, D.S . O ensino de química nas escolas da rede pública de ensino fundamental e médio do município de Itapetinga-BA: O olhar dos alunos.. In: ENCONTRO DIALÓGICO TRANSDISCIPLINAR - Enditrans, 2010, Vitória da Conquista, BA.

9. ROBAINA, J. V. L. Química através do lúdico: brincando e aprendendo, Canoas: Ed. Ulbra, 2008, 480p.

10. SOARES, M.H.F.B. O lúdico em química: jogos e atividades aplicados ao ensino de química. 2004. 203f. Tese (Doutorado em Ciências) - Centro de Ciências Exatas e de Tecnologia, Universidade Federal de São Carlos, São Carlos-SP, 2004.

11. TREVISAN, T. S.; MARTINS, P. L. O. A prática pedagógica do professor de química: possibilidades e limites. UNIrevista, São Leopoudo, RS, v. 1, n² 2 abril, 2006. 